\title{
Pulmonary arterial hypertension: guidelines and unmet clinical needs
}

\author{
D. Giuggioli', C. Bruni², F. Cacciapaglia ${ }^{3}$, F. Dardi ${ }^{4}$, A. De Cata ${ }^{5}$, N. Del Papa ${ }^{6}$, \\ F. lannone ${ }^{3}$, C. Lunardi ${ }^{7}$, W. Maglione ${ }^{6}$, F. Molinaro ${ }^{5}$, M. Palazzini ${ }^{4}$, A. Spinella ${ }^{1}$, \\ E. Tinazzi ${ }^{7}$, M. Matucci Cerinic ${ }^{2}$
}

'Scleroderma Unit, Rheumatology Unit, AOU of Modena, University of Modena e Reggio Emilia, Modena, Italy; ${ }^{2}$ Department of Experimental and Clinical Medicine, Rheumatology Unit, University of Florence, Florence, Italy; ${ }^{3}$ DETO-Rheumatology Unit, University Aldo Moro of Bari, Bari, Italy; ${ }^{4}$ Cardiology Unit, AOU of Bologna Policlinico S. Orsola Malpighi, Bologna, Italy; ${ }^{5}$ Rheumatology Unit, Medicine Unit, Casa Sollievo della Sofferenza-IRCCS-San Giovanni Rotondo, Foggia, Italy; ${ }^{6}$ Scleroderma Clinic, Sjogren Unit, UOC Day Hospital Rheumatology, ASST G. Pini-CTO, Milan, Italy; 'Department of Medicine, University of Verona, Verona, Italy

\section{SUMMARY}

The term pulmonary arterial hypertension (PAH) identifies a heterogeneous group of diseases characterized by a progressive increase in pulmonary arterial resistance (PVR), which causes a significant burden in terms of quality of life, right heart failure and premature death.

The pathogenesis of PAH is not completely clear: the remodeling of the small pulmonary vessels is crucial, causing an increase in the resistance of the pulmonary circle. Its diagnosis is based on cardiac catheterization of the right heart.

According to the present hemodynamic definition of pulmonary hypertension (PH) proposed by the Guidelines of the European Society of Cardiology/European Respiratory Society (ESC-ERS), the mean pulmonary arterial pressure (mPAP) values are $\geq 25 \mathrm{mmHg}$. In case of PAH, apart from an $\mathrm{mPAP}$ value $\geq 25 \mathrm{mmHg}$, patients must have a $>3$ Wood units increase in PVR and normal pressure values of the left heart. PH is a pathophysiological condition observed in more than 40 different diseases, while PAH is a primary disease of the pulmonary bloodstream potentially treatable with specific drugs.

$\mathrm{PAH}$ is a severe complication of systemic sclerosis (SSc) affecting about $10 \%$ of the patients. Due to the devastating nature of SSc-PAH, there is a clear need to systematically adopt appropriate screening programs. In fact, despite awareness of the negative impact of SSc-PAH on quality of life and survival, as well as on the severity of lung function, at the moment standardized and shared guidelines and/or screening programs for the diagnosis and the subsequent early treatment of PAH in SSc are not available.

The aim of the present paper is to highlight the lights and shadows of SSc-PAH, unraveling the unmet clinical needs on this topic with a proposal of clinical-diagnostic and therapeutic guidelines.

Key words: Pulmonary arterial hypertension, systemic sclerosis.

\section{Systemic sclerosis-associated pulmonary arterial hypertension: clinical-epidemiological}

7 he term pulmonary arterial hyperten-

sion (PAH) identifies a heterogeneous group of diseases characterized by a progressive increase in pulmonary arterial resistance (PVR), which leads to a significant reduction in terms of quality of life associated with increased disability, right heart failure and premature death.

The pathogenesis of PAH is not completely clear, but the main pathological feature is the remodeling of the small pulmonary vessels, causing an increase in the resistance of the pulmonary circle $(1,2)$.

The diagnosis of PAH is based on cardiac catheterization of the right heart, which is an invasive but relatively safe procedure when performed by experienced personnel (3).

According to the hemodynamic definition of pulmonary hypertension $(\mathrm{PH})$ proposed at present by the Guidelines of the European Society of Cardiology/European Respiratory Society (ESC-ERS), the mean pulmonary arterial pressure (mPAP) values 
are $\geq 25 \mathrm{mmHg}$ (4). In case of $\mathrm{PAH}$, apart from an mPAP value $\geq 25 \mathrm{mmHg}$, patients must have a $>3$ Wood units increase in PVR and normal pressure values of the left heart (pulmonary artery wedge - PAWP and/or left ventricular end-diastolic pressure - LVEDP $<15 \mathrm{mmHg}$ ) (3). This difference is important because $\mathrm{PH}$ and $\mathrm{PAH}$, which are frequently used as synonyms in clinical practice, are very distinct diseases. $\mathrm{PH}$ is a pathophysiological condition observed in more than 40 different diseases, while PAH is a primary disease of the pulmonary bloodstream potentially treatable with specific drugs (4).

Considering that the normal mPAP values do not exceed $20 \mathrm{mmHg}$, it has recently been proposed to lower the threshold for $\mathrm{PH}$ to $20 \mathrm{mmHg}$, while the value of PVR $\geq 3$ Wood units (3) associated with mPAP $>20 \mathrm{mmHg}$ remains valid for PAH. Although from a pathophysiological, scientific and prognostic point of view the reduction of the threshold to $20 \mathrm{mmHg}$ is correct, the impact of this value is not yet clear in terms of therapeutic choice. Indeed, most randomized controlled clinical trials have enrolled $\mathrm{PAH}$ patients according to the definition of the current ESC-ERS Guidelines (4). To date, only two small studies are available evaluating the efficacy of PAH drugs in patients with $\mathrm{mPAP}$ at rest $<25 \mathrm{mmHg}$, both in the context of systemic sclerosis (SSc) (3-7).

Since the symptoms of PAH are initially non-specific, most PAH patients receive a late diagnosis and therefore show a highly compromised clinical and symptomatic status, as well as severe hemodynamic features (8-10). Data from European PAH registries show that $72 \%-85 \%$ of patients are already diagnosed in functional class III or IV (11-13) according to the New York Heart Association (NYHA), with a diagnostic delay of 2-4 years between the onset of symptoms and the diagnosis $(14,15)$.

Despite the recent introduction of targeted therapies for PAH, the annual PAH-related mortality remains high, approximately $10 \%$ in the idiopathic form (16-19); the prognosis is poorer in PAH cases associated with SSc (20-27). Therefore, early de- tection of PAH with an mPAP value ranging from 21 to $24 \mathrm{mmHg}$ is not feasible in patients with idiopathic forms but in those who are at a high risk of developing them, such as BMPR2 mutation carriers and SSc patients.

PAH is a severe complication of SSc affecting about $10 \%$ of the patients. Due to the devastating nature of SSc-PAH, there is a clear need to systematically adopt appropriate screening programs. In fact, despite awareness of the negative impact of SScPAH on quality of life and survival, as well as on the severity of lung function, at the moment standardized and shared guidelines and/or screening programs for the diagnosis and the subsequent early treatment of PAH in SSc are not available (28).

\section{GENERAL ASPECTS}

The term screening procedure refers to the systematic use of one or more tests to diagnose a disease before the onset of clear symptoms in an at-risk population $(29,30)$. An ideal screening test should have high specificity and sensitivity for a specific disease, should be easily reproducible, noninvasive, inexpensive and easily accessible. Besides, screening for an asymptomatic disease should be carried out where confirmatory tests, as well as prevention and treatment programs can be applied.

Considering screening tests, it is firstly essential to reflect whether early diagnosis and a prompt targeted therapy could have a significant effect on the patient's prognosis; secondly, a possible over-diagnosis associated with a screening campaign must be considered (31). An over-diagnosis is possible when $\mathrm{PAH}$ is diagnosed in an early phase (i.e. asymptomatic disease), but it has an impact on the outcome if there is involvement of other organs and/or lifethreatening non-PAH-related comorbidities. This situation is particularly evident in elderly SSc patients, in severe and advanced systemic forms (lung, gastrointestinal tract and kidney) and cancer patients. The mortality in this subgroup of subjects is not strictly related to $\mathrm{PAH}$, especially in the presence of comorbidities or the in- 
volvement of other organs (23). In some cases, the risk related to diagnostic tests and treatment may be greater than the need for an early diagnosis. On this basis, we should not think that right cardiac catheterization is unnecessary in elderly patients or more advanced forms of SSc: this procedure can indeed provide important information even without a diagnosis of $\mathrm{PAH}$, especially if symptoms such as dyspnea, cough and asthenia are present. In these cases, the test will be able to detect postcapillary pulmonary hypertension relating to a left ventricular dysfunction (systolic or diastolic), interstitiopathy-related pulmonary hypertension, or a pulmonary hypertension associated with a deficit of cardiac output, for example in the presence of anemia or thyroid dysfunctions.

Another point to consider for PAH screening is to identify a real at-risk population (in the absence of signs or symptoms typical of the disease), compared with patients with early PAH or with mild symptoms. Most studies include symptomatic patients, primarily dyspnea, increasing the prevalence of the disease in the population and overestimating the risk-benefit ratio of the screening program, compared with truly asymptomatic patients. Similarly, in screening studies where most patients are symptomatic, the performance characteristics of screening tests (negative and/or positive predictive values) should be interpreted with caution and should not be compared through cohorts.

The prevalence of PAH in SSc is approximately $7-19 \%$ (32), sufficient to justify the need for a screening program (33-38); the incidence is about $1.5 \%$, a value increasing according to the duration as well as the variant of the disease (36-40). In fact, it is well known that in a period of 15 years, $18 \%$ of patients with diffuse skin variant and $24 \%$ of patients with a limited form develop PAH, respectively (40). The early diagnosis of SSC-PAH is very important because this condition is currently the cause of death in $30 \%$ of patients with $S(41)$.

Despite the availability of a targeted therapy for SSc-PAH, a combined improvement of symptoms, functional status and hemo- dynamic data is not always observed (11, $13,42)$. In fact, the long-term prognosis of these patients is poor and significantly worse than in patients with idiopathic $\mathrm{PAH}$, despite the use of appropriate treatments according to international guidelines. Early diagnosis and a prompt therapy, even in the absence of symptoms, are crucial to increasing short- and long-term survival. Compared with previous 3-year survival data of SSc-PAH of approximately $50 \%$ (22), the most recent PHAROS study showed an improvement in survival at 1,3 and 5 years of $95 \%, 75 \%$ and $63 \%$, respectively (23). These data refer to a population undergoing systematic diagnostic screening and consequently with an early diagnosis (23). In fact, patients enrolled in the PHAROS study showed milder symptoms at diagnosis with $59 \%$ of patients in functional class NYHA I or II. This confirms that early diagnosis and targeted therapy are associated with better long-term outcomes. The use of systematic screening, such as occurred in the PHAROS study, increases the number of early diagnoses, but could have some bias, in particular the risk of over-diagnosis as well as lead-time, as illustrated in Figure 1.

\section{Screening procedures in SSc: best practices}

Transthoracic echocardiography

To date, transthoracic echocardiography (TEE) is the most frequently used test for the screening of SSc-PAH. According to ESC/ERS Guidelines $(4,43)$ and systematic reviews of literature from 2014 to 2019 (44-46), a yearly TTE is recommended in SSc patients with or without symptoms.

The tricuspid valve regurgitation velocity (TRV) and other indirect signs of $\mathrm{PH}$, such as the dilation of the right section of the heart, the presence of pericardial effusion and the dilation of the inferior vena cava, are used to determine the probability of developing $\mathrm{PH}$.

2D-speckle tracking echocardiography makes it possible to estimate the strain on the right atrium (RA) and the right ventricle (RV) of the heart. In particular, the echostrain can detect occult dysfunctions of the 


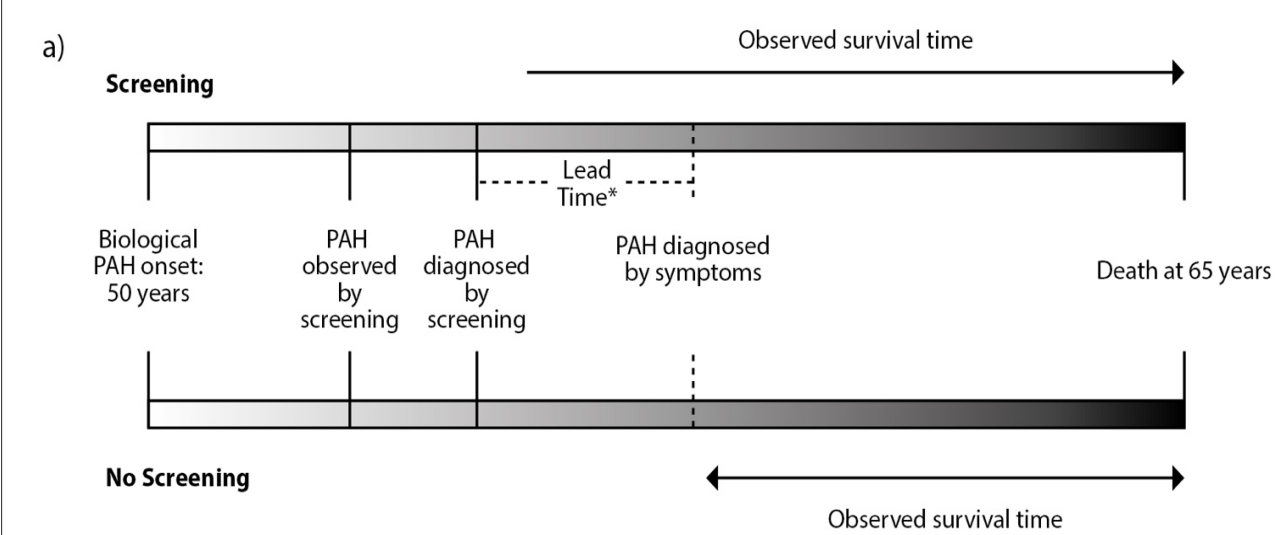

b)

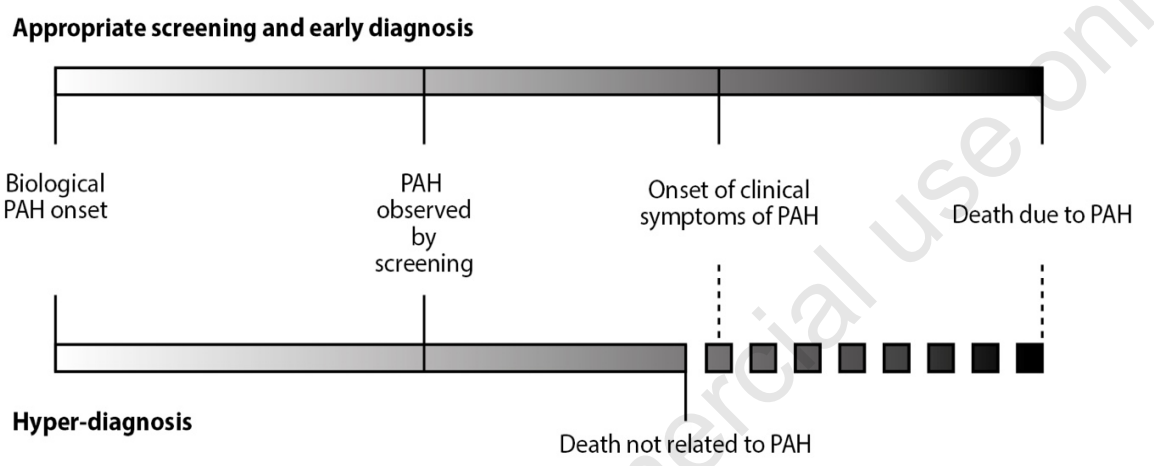

Figure 1 - Epidemiological concepts for screening programs of PAH. A) lead-time bias; B) hyper-diagnosis.

right heart and shows an increased RV postload when the TRV is not high, even before the evidence of cardiac dilation or other echocardiographic signs of cardiac damage (47-49). A recent study shows that a deformity systolic longitudinal peak of $14.48 \%$ at the apical segment of the lateral wall of RV has a $100 \%$ specificity for $\mathrm{PAH}$ development in patients with SSc (49). However, the echo-strain presents some limitations of TTE, such as an operator-dependent evaluation; moreover, RV strain may indicate myocardial fibrosis (a typical and possible sign in $\mathrm{SSc}$ ) rather than a postload alteration (47). Further studies are therefore needed to assess the real efficacy and the large-scale role of 2D-speckle tracking echocardiography for the PAH screening in asymptomatic patients with SSc.

Right heart catheterization is recommended when patients have an intermediate or high risk of developing $\mathrm{PH}$, based on echo- cardiographic data, defined as a TRV peak $>2.8 \mathrm{~ms}-1$, or a TRV $<2.8 \mathrm{~ms}-1$ (or not measurable) associated with other variables suggestive of $\mathrm{PH}$ (38).

Although echocardiography is the gold standard of screening methods, it has a low predictive value related to the method, the patient and the operator. As regards the method, it should be noted that approximately $15 \%$ of patients undergoing echocardiography have an inadequate estimate of tricuspid regurgitation, and therefore a TRV that cannot be evaluated (41). Moreover, some patient-associated limitations, such as obesity and/or deformity of the thoracic wall, can make the outcome of the test unreliable. Last but not least, the ultrasound method is still operator-dependent.

Tests of lung function

A reduction in the diffusion of lung carbon monoxide (DLCO) with normal forced vi- 
tal capacity values (FVC) is frequently observed in SSC-PAH patients (50). However, the ongoing DLCO reduction during $\mathrm{SSc}$ is frequently associated with pulmonary fibrosis and obstructive syndrome, which should be considered in the differential diagnosis (51). A DLCO reduction during the follow-up period should always be considered a sign of possible PAH development, particularly in patients with a limited skin form and without lung interstitial engagement (52). A predicted DLCO value $>60 \%$ can, although with obvious limitations, exclude the presence of PAH (53, $54)$. Conversely, a DLCO value $<50 \%$ has a high specificity (90\%) and a high positive predictive value (53). However, it should be noted that normal DLCO values do not exclude a priori the presence of PAH. Some studies evaluating DLCO components, such as membrane conductance, showed conflicting results. Further studies are therefore needed to evaluate the actual role of these parameters in improving the screening for SSc-PAH patients, as well as to identify their role as potential indicators for other parameters, such as exhaled NO (54-56).

\section{Cardiopulmonary exercise testing}

Echo-stress and cardiopulmonary stress tests are not currently recommended in SSc-PAH screening (4). Patients with SSc frequently show an impaired hemodynamic response to physical exercise even when resting hemodynamic data are normal; this may be related either to early pulmonary vascular engagement or to a predominant diastolic left heart dysfunction (heart failure with preserved ejection fraction) (24, 57-59). During PAH, a reduction in peak oxygen consumption, a ratio of oxygen consumption to heart rate, work rate, work threshold, and an increase in the ratio of ventilation to $\mathrm{CO}_{2}$ production are frequently observed (60). These parameters can also be impaired in other diseases; for this reason, the test must necessarily be interpreted taking into account the possible metabolic, cardiovascular or pulmonary components, which could have a significant impact on its results (61). The change in pulmonary sys- tolic blood pressure (PAPs) during exercise echocardiography may be related to the presence of $\mathrm{PH}$, as demonstrated by Codullo et al. (62), but at the moment poor precision in the measurement of PAPs and cardiac output during exercise does not place the test among those recommended for SSC-PAH screening. Furthermore, an increased PAPs is not necessarily the expression of PAH: in most cases it may be secondary to an increased stress wedge, suggestive of heart failure with preserved ejection fraction. In conclusion, although more recent data have highlighted the possible role of cardiopulmonary stress tests for the diagnosis of early $\mathrm{PAH}$, prospective longitudinal trials are needed in order to clarify the role of CPETs in the screening of this patients subset.

\section{Cardiac magnetic resonance imaging}

The role of cardiac magnetic resonance imaging (MRI) in the diagnosis of PAH is not yet well established, but this procedure is essential for the overall evaluation of the heart in patients with SSc. Cardiac involvement is very common during $\mathrm{SSc}$ and myocardial fibrosis is present in 50$80 \%$ of post-mortem cases, even though its clinical evidence is rare. The fibrotic myocardiopathy can cause a dysfunction of the left heart, and the patient is at high risk of arrhythmic and ischemic complications, associated with the development of post-capillary pulmonary hypertension (group 2 of the diagnostic classification) (4). Recent trials have shown that cardiac MR is a very sensitive procedure for identifying myocardial fibrosis in SSc patients and can therefore represent an essential screening test during the diagnostic procedure for suspected pulmonary hypertension, able to distinguish group $1(\mathrm{PAH})$ and group 2 pulmonary hypertension (63, 64).

\section{Biomarkers}

The natriuretic peptide NT-proBNP is the most widely used biomarker in SSc, both in trials and in clinical practice. A unique value of NT-proBNP appears inadequate for screening because of its low sensitivity 
(56-69\%) and its low negative predictive value, since it may be normal in patients with an early disease stage in which the right heart is not yet involved $(65,66)$. In addition, NT-proBNP is not specific for right ventricular dysfunctions in $\mathrm{PAH}$ patients, because it can also be impaired in patients with left heart failure or renal failure, conditions also observed in patients with SSc (67). This biomarker may be useful in combination with other screening tests, such as echocardiography and respiratory function tests, and it is used in screening algorithms with values higher than those considered in the normal range (204-395 pg/mL) $(38,65,66,68-71)$.

Recent data show that troponin and highsensitivity troponin can be used as possible biomarkers for the diagnosis of SSc-PAH, but further trials are needed to confirm their actual role (68).

In 2015, Shirai et al. demonstrated that the level of pentraxin 3 (PTX3), a multifunctional model recognition protein able to suppress the fibroblast growth factor 2 (FGF-2), was high in SSc-PAH patients, and FGF-2 level was significantly reduced. The authors therefore concluded that exposure to high concentrations of PTX3 could interfere with the activity of endothelial progenitor cells (EPC) responsible for impaired vasculogenesis, and thus promote the development of PAH (72).

The red blood cell distribution width (RDW) is a simple, readily available marker able to predict $\mathrm{PAH}$ in patients with $\mathrm{SSc}$ $(\mathrm{OR}=3314$ [IC 95\% 1.038-10.580], p $<0.05)$ and has therefore been proposed for the screening of SSc patients (73). Similarly, high serum levels of uric acid (AU) are associated with an increased risk of $\mathrm{SSc}-\mathrm{PAH}$ and AU has been included in the DETECT algorithm (74).

As far as SSc-related auto-antibody specificities are concerned, anti-centromere antibodies (ACA) are known to be associated with the risk of developing PAH (75), while anti-topoisomerase I (anti-Scl70) seem to be protective (76).

Further studies are needed to demonstrate the diagnostic and predictive value of blood markers in asymptomatic subjects or in at- risk populations. In addition, more studies are also needed to identify possible genetic biomarkers associated with SSc-PAH.

\section{Screening algorithms}

Recent studies show that the use of composite measures (algorithms) within SScPAH screening is associated with a better outcome (46). Among the composite assessments for SSc-PAH, ESC/ERS Guidelines are the most widely used, alongside the DETECT algorithm and the Australian Scleroderma Interest Group (ASIG) algorithm $(4,38,69,70)$.

The ESC/ERS Guidelines recommend yearly echocardiography screening in asymptomatic patients with SSc, followed by the evaluation of biomarkers and DLCO. DETECT was the first evidence-based study for the screening of PAH in SSc patients (38). The objectives of the study, based on a rigorous methodology, were to evaluate the performance of screening characteristics (sensitivity and specificity), to assess its application in real life, to identify asymptomatic patients at risk of developing a PAH, to minimize lost diagnoses and to optimize the diagnostic application of RHC. DETECT, a battery of non-invasive tests followed by a diagnostic confirmation through RHC, evaluated patients with SSc diagnosed more than three years before and DLCO predicted values $<60 \%$. The DETECT algorithm consists of two steps, the first of which is based on non-echocardiographic parameters: FVC/DLCO, presence of telangiectasias, anti-centromere antibody (ACA) positivity, impaired values of NTproBNP and uric acid, right axial deviation in the standard ECG. If the total risk score of the first step exceeds 300 points, the patient undergoes the second step, which evaluates echocardiographic variables, such as right ventricle area and TVR. If the second step score is $>35$, the patient will perform RHC.

DETECT has a high sensitivity; its application is able can reduce misdiagnosis when compared with ESC/ERS Guidelines and optimizes resources by limiting the use of the more expensive and invasive methods to a limited population of real high-risk pa- 
tients with SSc. A Norwegian study showed that, in case of correct application of the DETECT algorithm, the percentage of SSc patients with a mPAP value between 20-24 $\mathrm{mmHg}$ rises from $17 \%$ to $31 \%$ (77).

The ASIG algorithm is also based on two components: A, with a DLCO $<70 \%$ and a FVC/DLCO value of at least 1.8 , and $\mathrm{B}$ (based on NT-proBNP values $>210 \mathrm{pg} /$ $\mathrm{mL}$ ). The screening is considered negative if both components $\mathrm{A}$ and $\mathrm{B}$ are absent, but positive if either or both are present.

If the screening is positive, patients must undergo echocardiography associated with other confirmatory tests, i.e. high-resolution axial computed tomography (HRCT) of the chest and the 6 minute walking test (6MWT); finally, if no impairments to these tests are detected concerning parenchymal lung involvement, RHC should be performed.

Figure 2 shows the screening algorithm for PAH patients.

\section{Critical aspects}

Due to the need to identify patients with $\mathrm{SSc}$ at risk of developing PAH, to diagnose this complication, and to early-start a ther- apy that may have an impact on the patient's prognosis (22-24), scientific evidence and clinical practice have highlighted some critical issues. The recent literature review on screening for PAH associated with connective tissue diseases by Young et al. showed that only 22 out of 1514 recent studies met the criteria for a correct diagnosis of $\mathrm{PAH}$, including the cardiac catheterization at the end of the diagnostic path (45). Moreover, as recently pointed out by Smith et al., the lack of evidence-based and consensus-based guidelines results in an unmet need in the management of many aspects of SSc, including PAH $(78,79)$.

The recommendations for the early diagnosis of SSc-PAH are mainly based on consensus and on the use of non-specific symptoms, echocardiographic data (29.30), as well as biomarkers and respiratory function tests.

The characteristics of the ideal screening for SSc-PAH are: sensitivity and specificity for $\mathrm{SSc}$, reproducibility, non-invasive, cheap and easily executable. Because at present no procedures satisfy all these criteria, the early diagnosis is affected by the intrinsic limita-

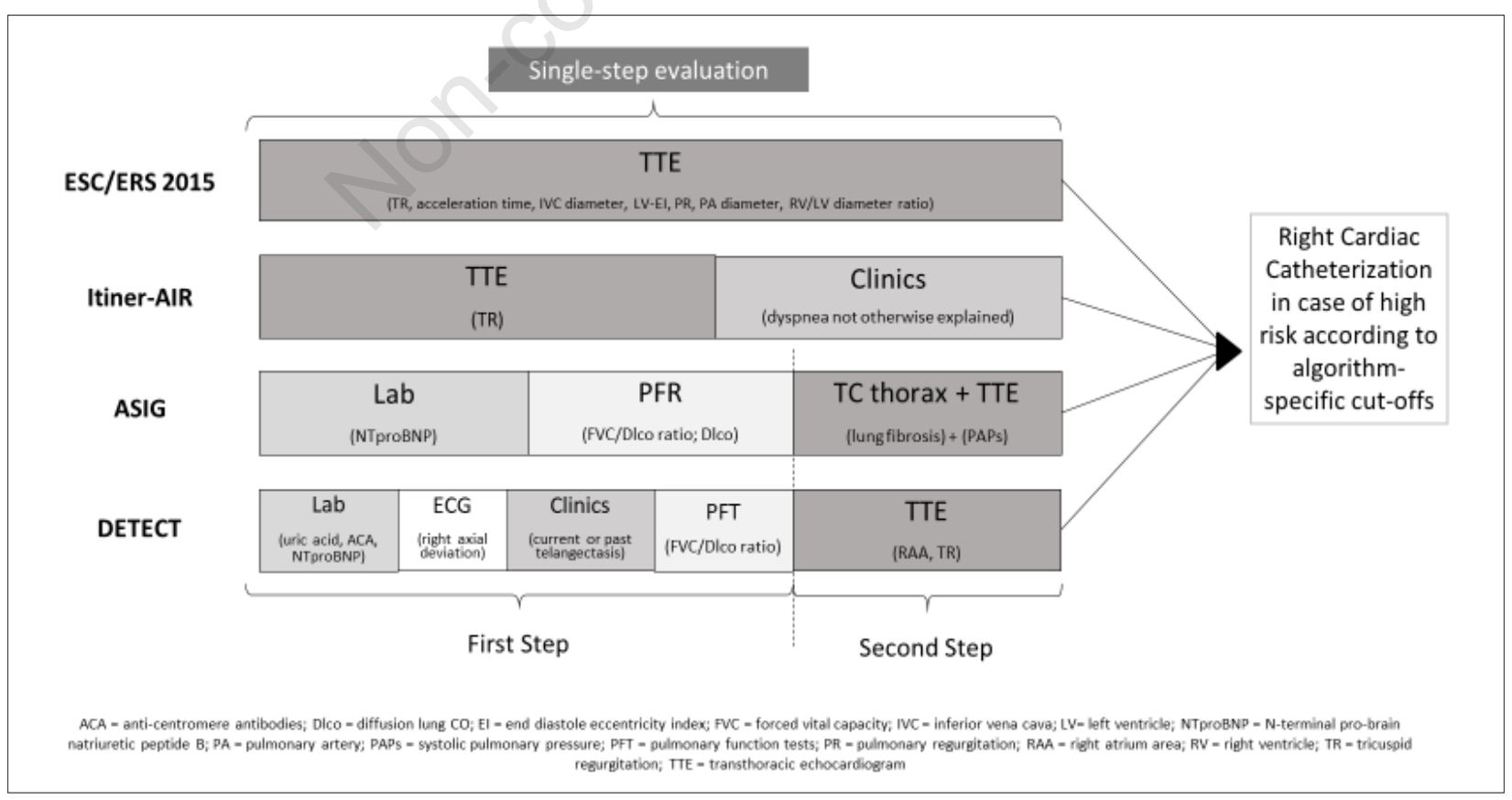

Figure 2 - Screening algorithm for PAH patients. 
tions of the different laboratory and imaging procedures, to be used simultaneously for diagnosis.

One of the main critical points for the diagnosis of SSc-PAH is the interpretation of the echocardiographic data. The main limitations of cardiac color Doppler echography are the evaluation of TRV in the absence of an adequate tricuspidal regurgitation (present in $15 \%$ of REF patients), and constitutional elements of the patient, which can lead to hyperinflation or deformity of the chest wall (38). There is also a limitation relating to the operator performing the echocardiographic test, since operators must be trained and experienced in the evaluation of patients with SSC and must know the minimum core-set of echocardiographic data necessary for the assessment of PAH in the SSc patient.

Recently two dimensional speckle tracking has been proposed for the early diagnosis of SSc-PAH, although this procedure needs to be evaluated in specific clinical trials and validated to define its positive predictive value. In addition to echocardiographic parameters, NT-proBNP and the reduction of DLCO values are also used, each with a low predictive value if considered individually. For this reason, diagnostic algorithms have been proposed in order to increase the predictive effectiveness in diagnosis, using a combination of several clinical-laboratory and instrumental parameters.

The application of SSc-PAH screening algorithms improves the clinical outcomes; however, also in this case there are some critical issues relating to the use of DETECT and ASIG algorithms. Considering the DETECT algorithm, the unresolved weaknesses concern its long-term performance, the frequency of patient evaluation, and the limitation related to the selection of the patient with SSc lasting less than three years and DLCO values $>60 \%$. Only one study evaluated the DETECT algorithm in a non-selected population of SSc patients, showing an improvement of the diagnosis of PH-borderline cases; however, further studies are certainly needed (38). As regards the ASIG algorithm, which has a high specificity and sensitivity for SSc$\mathrm{PAH}$, more extensive studies are needed, as well as validation trials on the performance of this algorithm, which are desirable but not yet available to validate the effectiveness of this tool $(69,70)$.

Another clear unmet need is the evaluation of the performance of these SSc-PH diagnostic algorithms in patients with pulmonary interstitial disease, because this complication is frequent in SSc patients, reaching $50-70 \%$ in patients with SSc (43).

Finally, a critical element for the early detection of PAH is the different use of screening methods in routine clinical practice in the different centers (I and II level). In particular, physicians' adherence to the application of the screening indices is suboptimal and the yearly echocardiogram is performed infrequently in patients with SSc outside the reference centers (36). Only $34.7 \%$ of SSc patients perform an echocardiogram, only $53.1 \%$ perform PFR and DLCO and, in the high-risk group for $\mathrm{PAH}$, only $59 \%$ perform a right catheterization (36). Similarly, despite the clear need for algorithms (ESC/ERS guidelines, DETECT and ASIG), more effective for early identification of SSc-PAH patients than the usual care alone $(4,38,69,70)$, their use is still very limited outside reference centers.

The requests from rheumatologists to improve compliance in the application of SSc-PAH-related algorithms are:

1) clearer and simpler guidelines;

2) easy and cheaper survey methods;

3) careful selection of patients;

4) access to regular screening and followup;

5) the possibility of having a reminder system.

\section{Signs/symptoms predictive of PAH in SS patients}

PAH is currently the main cause of death in SSc patients. New drugs are more effective and significantly prolong survival when administered in the early phase of PAH. The availability of predictive signs of SSc-PAH is therefore crucial for a prompt and effective treatment strategy. 


\section{Diagnosis and follow-up of PAH during SSc}

Early detection of PAH is a key step in the clinical history of SSc patients, as it represents a frequent and severe complication, characterized by a worse prognosis than idiopathic/hereditary PAH or PAH associated with congenital heart disease. The diagnosis of SSc-PAH is more difficult than that of idiopathic PAH, due to the possible multiorgan localization of SSc. Indeed, the SSc patient may fall into any group of the ESCERS clinical classification of PH (4). He/ she may have pulmonary arterial hypertension associated with vasculopathy (group 1 of the diagnostic classification), in which the use of specific drugs is indicated; a pulmonary hypertension secondary to left heart diseases (group 2); pulmonary diseases (group 3); or an IP-PH secondary to thromboembolic disease (group 4). The SSc patient may also have a veno-occlusive form (group 1), characterized by the involvement of venules as well as arterioles (80).

Although recent studies suggest that early therapy can improve the prognosis in both idiopathic and SSc secondary forms of PAH $(81,82)$, it is necessary to detect this complication early through a screening program. The initial non-specific symptoms and signs are mainly exertional dyspnea, asthenia, angina-like chest pain, palpitations, dizziness and sloping edemas; lipothymia and syncope can be observed in more advanced stages.

The ESC-ERS Guidelines confirmed the gold standard role of right cardiac catheterization for the diagnosis of $\mathrm{PH}$ (4). Although it is an invasive procedure, it has low morbidity $(1.1 \%)$ and mortality $(0.055 \%)$ when performed in expert centers (83).

To avoid unnecessary catheterizations, it is essential to select the appropriate population for this procedure. The diagnosis is performed through the screening tests mentioned above.

In conclusion, current guidelines recommend an annual screening of asymptomatic SSc patients though an echocardiographic evaluation, lung function tests and some biomarkers, including NT-proBNP and uric acid. A regular periodic screening is

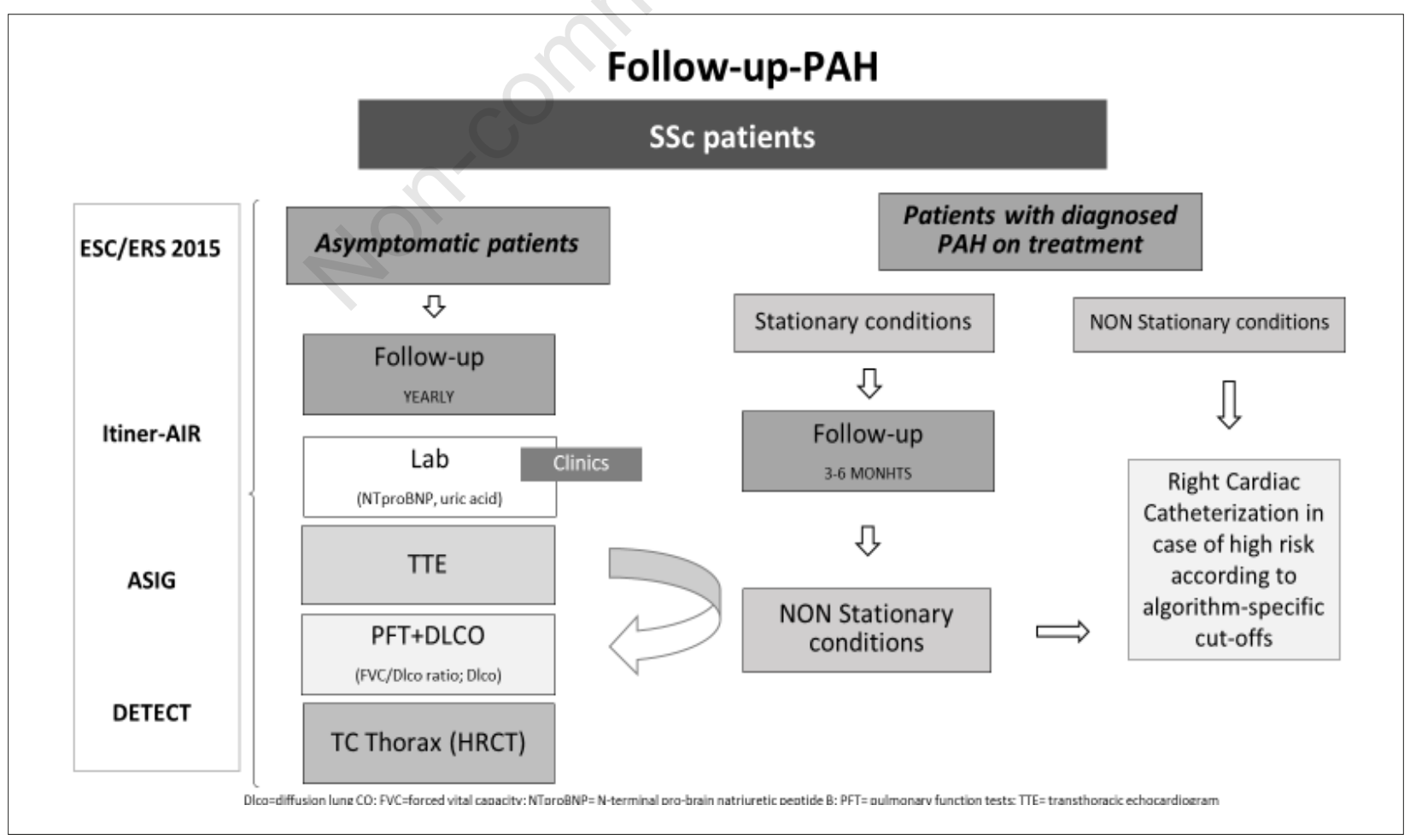

Figure 3 - Follow-up of PAH patients. 
able to improve patients' survival by identifying patients with an early PAH (Figure 3) $(84,85)$.

\section{TREATMENT}

The treatment of PAH (group 1 of the clinical classification) has recently shown significant progress and more awareness as to how to use drugs in combination to achieve a therapeutic result (86).

Until a few years ago, only non-specific drugs were available for the treatment of right ventricular decompensation (digitalis, diuretics), and not for the correction of hypertensive pulmonary vasculopathy. Over the last 25 years, 41 randomized controlled clinical trials on 9061 patients with $\mathrm{PAH}$ have led to the approval by the regulatory agencies of specific drugs for the correction of the biochemical dysfunctions observed in the endothelin, nitric oxide and prostacyclin pathways, responsible for the alterations in endothelial physiology and consequently for hypertensive pulmonary vasculopathy $(80,86-88)$. These drugs have four routes of administration: oral, inhalatory, subcutaneous and intravenous (the last two requiring training of the patient and family members). Considering the poor prognosis and the high heterogeneity of clinical presentation and evolution of PAH, the therapeutic management is based not only on administration of drugs, but on a complex, structured strategy that includes the use of general and supportive measures, the search for the pulmonary vasoreactivity, the evaluation of the disease severity, the regular monitoring of the treatment outcome and the possible use of invasive therapeutic procedures (mainly lung transplantation).

Moreover, we must not forget that, in most cases, PAH is a complication of another disease or syndrome and therefore a multidisciplinary approach is essential (89-91).

\section{Supportive drug therapy}

\section{Diuretics}

Right heart failure is responsible for fluid retention, increased central venous pressure, abdominal organ congestion, ascites and peripheral edema. Although no clinical studies have evaluated the efficacy of diuretics in PAH patients, clinical experience shows that their use in the presence of right heart failure is associated with favorable clinical effects. The choice of type and dose of the diuretic to be used in the different patients comes under the responsibility and experience of physicians, requiring in any case dosage adjustment based on clinical response, parameters of renal function and serum and urinary electrolytes.

\section{$\mathrm{O}_{2}$-therapy}

Most PAH patients (with the except for $\mathrm{PAH}$ associated with congenital heart disease) have only a mild resting arterial hypoxemia. In these cases, the pathophysiological mechanism is the decreased $\mathrm{O}_{2}$ saturation of mixed venous blood due to the reduction in cardiac output and, to a lesser extent, impairments of alveolar-capillary exchanges. A more severe arterial hypoxemia is generally associated with the presence the oval foramen, in this case not improved by oxygen supplementation, or to the concomitant presence of restrictive/obstructive respiratory failure. In case of severe hypoxemia in SSc-PAH patients, a pulmonary veno-occlusive lung disease (MVOP), where arterioles and venules are involved, must be excluded. In case of suspected MVOP, the combination of clinical, spirometric (including carbon monoxide diffusion capacity) and radiological information enables us, with a good approximation, to have a diagnostic confirmation without performing a pulmonary biopsy, contraindicated in patients with pulmonary hypertension $(92,93)$.

ESC-ERS 2015 Guidelines (4) recommend administering oxygen therapy whenever the $\mathrm{pO}_{2}$ value, evaluated through arterial hemogasanalysis, is consistently $<60 \mathrm{mmHg}$. However, this recommendation is based on data deriving from patients with chronic obstructive pulmonary disease rather than from patients with PAH.

\section{Oral anticoagulants}

The rationale for the use of oral anticoagulant drugs in PAH patients is based on several elements: 
1) frequent post-mortem findings of thrombotic lesions in the pulmonary microcirculation and elastic pulmonary arteries $(94,95)$;

2) documented impairment of coagulation processes and thrombophilic predisposition (96);

3) presence of generic risk factors for venous thrombo-embolism, such as heart failure and sedentary lifestyle. The evidence in favor of treatment with oral anticoagulant drugs is based on retrospective analysis and monocentric trials rather than on randomized trials, and it is limited to patients with idiopathic PAH or PAH associated with anorexic drugs (96).

Nevertheless, in a period where many specific drugs for the treatment of endothelial dysfunction are available, the role of anticoagulant drugs in the treatment of PAH is uncertain. In fact, data from more recent studies and registries are conflicting and inconclusive (97-99).

As far as the use of oral anticoagulant drugs in SSc-PAH is concerned, there are more shadows than lights (100): the risk-benefit ratio of anticoagulant drugs in a patient with SSc-PAH is not favorable in most cases, given an increased risk of bleeding from the gastrointestinal tract.

In conclusion, in this subset of patients, anticoagulant drugs should only be started if there is an increased thrombophilic risk (positivity for LAC and/or antiphospholipid antibody syndrome) or if a tunneled central venous catheter is present.

\section{Antiarrhythmics}

Some drugs such as digitalis, widely used before the availability of the specific therapy for their positive inotropic effect, are currently used only for reducing the ventricular response rate in the presence of atrial tachyarrhythmias.

\section{Target therapy}

The general precautions for patients with idiopathic PAH, such as to avoid pregnancy and high altitude locations, maintain normal levels of $\mathrm{Hb}$ and perform mild aerobic physical activity in order to conserve a good per- formance of the respiratory muscles, are also valid for SSc-PAH patients (101).

The therapeutic algorithm of ESC-ERS 2015 Guidelines (4), recently updated after the VI World Symposium on Pulmonary Hypertension (102, 103), which includes specific treatments, can be used for SScPAH patients too. In fact, about $30 \%$ of patients enrolled in pivotal randomized controlled clinical trials had a PAH associated with connective diseases, which represent the second most frequent cause of PAH after the idiopathic form. The most important progress in the medical management of PAH has not been the discovery of new metabolic pathways, but the development of new therapeutic strategies (combination and escalation therapy) based on the systematic evaluation of the clinical response $(102,103)$.

Before starting the therapy, the therapeutic strategy proposed by the updated therapeutic algorithm recommends a pulmonary vasoreactivity test (only if indicated) and a multiparametric evaluation of the patient's risk profile. Although the remodeling of pulmonary arterioles is the main pathological finding in $\mathrm{PAH}$, the pulmonary artery vasoconstriction still has an important role in the pathophysiology of PAH in patients who are responsive to calcium channel blockers. The identification of these patients is based on a pulmonary vasoreactivity test performed during the baseline hemodynamic evaluation (the cornerstone of the diagnostic process), with the aim to select acute responder patients (104). However, the pulmonary vasoreactivity test should only be performed in patients with idiopathic, hereditary $\mathrm{PAH}$ associated with the use of anorexic agents. In SSc-PAH patients, the usefulness of the acute vasoreactivity test and the chronic treatment with calcium channel blockers is less evident and therefore not indicated $(105,106)$. The presence of pulmonary vasoreactivity during the acute test in these patients is not able to predict the favorable response of the long-term therapy with calcium channel blockers; besides, these patients can rarely tolerate high doses of these drugs (21). In conclu- 
sion, the empirical use of high-dose calcium channel blockers for pulmonary vasodilation is contraindicated in SScPAH patients, but a low-dose therapy can have a rationale in patients with Raynaud's syndrome.

In SSc-PAH patients, as well as in patients with idiopathic PAH who do not respond to the acute pulmonary vasoreactivity test, the best therapeutic strategy should be initiated after a multiparameter assessment of the patient's risk profile.

All-together, clinical status, exercise performance, functional class, right ventricular function and hemodynamic parameters are able can define a low, intermediate or high-risk profile based on the expected 1 -year mortality. It is important to stress that the therapeutic algorithm proposed by the guidelines does not apply to other pulmonary hypertension clinical groups; in particular, it is not valid for the treatment of patients with pulmonary hypertension secondary to left heart disease and chronic pneumopathy (group 2 and group 3 of the diagnostic classification, respectively) (3). In fact, the use of a specific therapy in these forms is contraindicated regardless of the possible presence of an underlying connective tissue disease (107).

The objective of the treatment for $\mathrm{PAH}$ patients is to achieve and maintain a low risk profile during a structured clinical, instrumental and hemodynamic follow-up. This recommendation and, generally, the multiparameter approach to the risk stratification have recently been validated by retrospective trials performed on 3 large independent registries (including 3135 patients), which show a significant difference in terms of 5-year mortality and transplantation-free survival according to the risk category concerning both baseline and first follow-up. Two out of 3 registers also included patients with PAH associated with connective tissue diseases (108110).

After confirmation of the diagnosis in a reference center, the initial therapeutic approach in a treatment-naive PAH patient is based on general measures and the abovementioned supportive therapy. In low- or intermediate-risk patients, an initial combination with an endothelin 1 receptor antagonist (ERA1) and a phosphodiesterase 5 inhibitor (PDE5i) is indicated (102). The Ambition study, performed on a large population of PAH patients, showed that this therapeutic strategy based on an initial combination therapy is more effective in reducing the composite endpoint (comorbidities and mortality) than a monotherapy with a single specific drug (ERA1 or PDE5i) (111). It should be noted that about $40 \%$ of the patients enrolled in this study were affected by PAH associated with connective tissue diseases in whom the results were similar to those observed in idiopathic PAH.

In elderly patients ( $>75$ years), where multiple risk factors for heart failure with preserved ejection fraction (diabetes mellitus, atrial fibrillation, obesity, systemic arterial hypertension, coronary artery disease), comorbidities (112) and high clinical-instrumental suspicion of pulmonary veno-occlusive disease may be present, the use of a specific monotherapy should be considered. This therapeutic decision can also be adopted in patients pre-treated with a longterm monotherapy ( $>5-10$ years) and with a documented low-risk profile at follow-up. Due to the lack of direct comparison trials between the different molecules, there is no preferred drug or class for first-line monotherapy. The choice of the molecule will be based on multiple factors, such as its administration route, safety profile and drugdrug interactions, and patient's comorbidities.

In high-risk patients, the use of an initial combination therapy including a prostacyclin analogue, possibly by intravenous route, is indicated. Intravenous epoprostenol has the highest level of clinical evidence, because it is effective even as a monotherapy in reducing 3-month mortality in patients with high-risk PAH (113). However, different combinations with other prostanoids (e.g. treprostinil sc) may also be considered.

In patients treated with a multidrug schedule (3-drug combination therapy with a PDE5i, a ERA and a prostacyclin ana- 
logue, preferably by IV route), screening for rapid detection of suitability for 2-lung transplantation should always be considered.

Physicians may consider the switch from one specific PAH therapy to another based on multiple factors, such as a better safety profile or optimal treatment adherence. However, at the state of the art, no evidence is available concerning the switch from sildenafil or tadalafil to riociguat in terms of symptoms improvement or survival $(103,114)$. For that reason, this therapeutic strategy is not recommended. Therefore, in case of unsatisfactory response to PDE5i plus ERA1, physicians could consider adding a third class of drugs rather than switching to another drug.

As already mentioned, the treatment of PAH is not a simple pharmacological prescription. After the start of the specific therapy, a multiparameter re-assessment of the patient's risk profile is indicated. If the initial therapeutic approach leads to the achievement of a low-risk profile after 3-6 months, physicians are recommended to continue the current therapy and to plan a structured follow-up. If the patient reaches or maintains an intermediate risk profile, the therapeutic outcome should be considered unsatisfactory and an escalation to triple therapy (if a combination therapy has been used) or a sequential dual therapy (in case of initial monotherapy) should be proposed. The most studied combination therapies are sildenafil plus macitentan (115), riociguat plus bosentan (116), selexipag plus ERA1 and/or PDE5i $(117,118)$. The combination of riociguat and a phosphodiesterase 5 inhibitor is contraindicated. Therefore, as is commonly observed in clinical practice, if a PAH patient has an intermediate (i.e. unsatisfactory) risk profile at the follow-up visit despite a combination therapy with ERA1 plus PDE5i, the addition of a prostacyclin receptor agonist should be considered, once the possible presence of the veno-occlusive disease is excluded. The GRIPHON study showed that the addition of selexipag in PAH patients (both idiopathic and SSc-PAH) already treated with a dual therapy is able

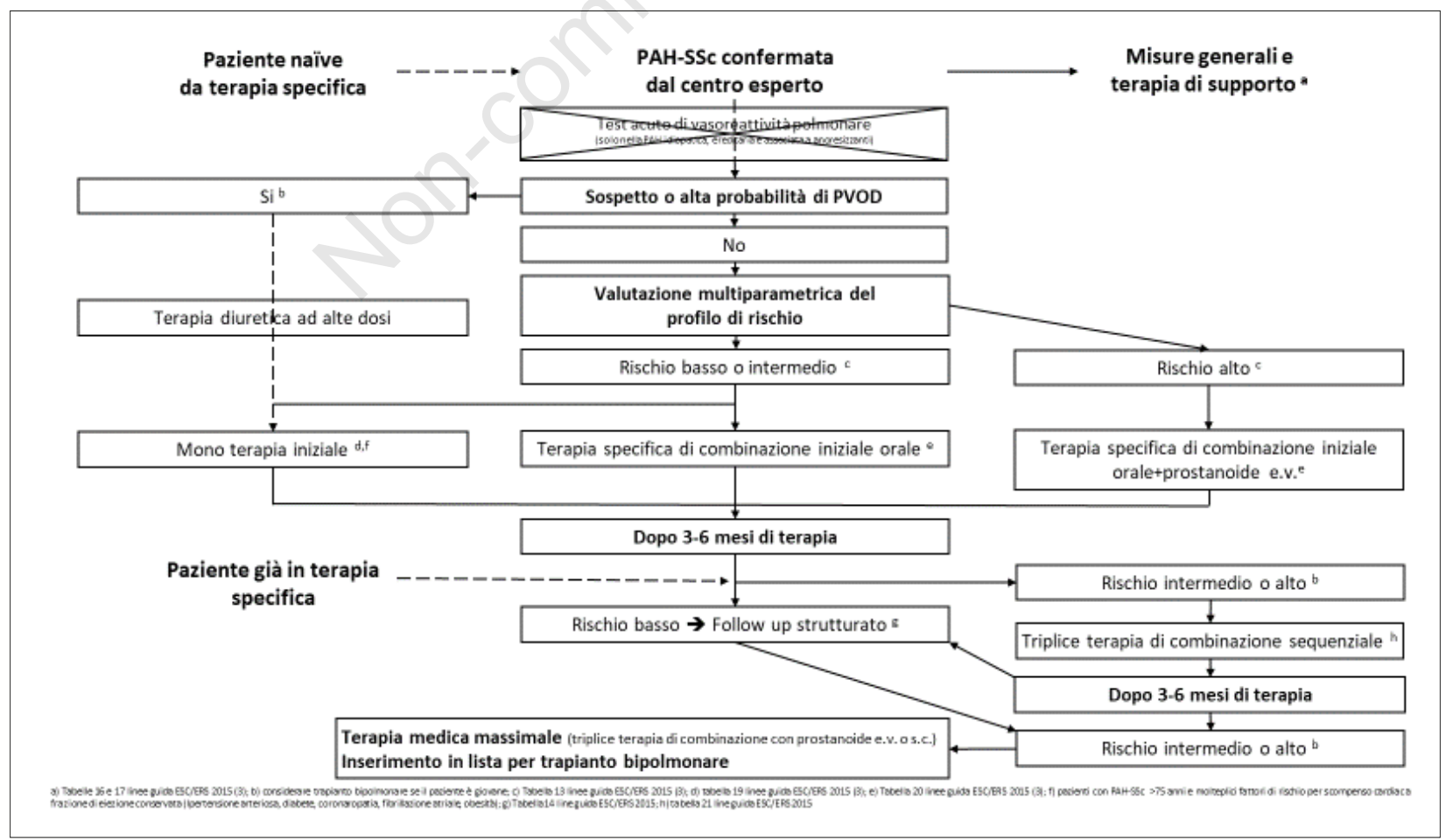

Figure 4 - Therapeutic algorithm for $\mathrm{PAH}$. 
can improve the composite endpoint of morbidities and mortality (117). If the patient reaches a low-risk profile 3-6 months later, he/she must continue the current therapy and plan a structured follow-up; an injective prostacyclin is indicated if the patient remains at intermediate risk or reaches high-risk status.

If the patient maintains or achieves a high risk profile despite the initial therapy, the use of a maximum therapy is indicated, as well as a prompt referral to a third level center to establish suitability for lung transplantation. Lung transplantation is generally the last therapeutic option for PAH patients who fail medical therapy. The presence of a connective tissue disease is not an absolute contraindication to 2-lung transplantation; however, these patients frequently have comorbidities and other organ dysfunctions which increase the risk of complications. For example, esophageal motility disorder and gastroesophageal reflux in patients with SSc significantly increase the potential post-surgical inhalation of materials, as well as lung damage (ab-ingestis pneumonia). For these reasons, it is extremely important that transplant candidates must be assessed on an individual basis, not only cardiologically but also from an internal and/or gastroenterological point of view, through appropriate procedures (esophageal impedance, gastroscopy, pHmetry).

A recent French trial compared the survival of SSc-PAH patients during two distinct periods: 2006-2011 and 2012-2017 (119). No statistically significant differences in terms of survival between the two periods were observed in the overall population. The analysis of the subgroup of patients aged $<70$ years showed that survival was longer in the period 2012-2017 than in the period 2006-2011. This could be explained by a better early diagnosis (due to intensified screening programs) and by an increased use of first-line combination therapy in the latter period. This study also confirms that first-line combination therapy is not useful in elderly patients with comorbidities. Figure 4 shows a therapeutic algorithm for $\mathrm{PAH}$.

\section{CONCLUSIONS}

In conclusion, according to ESC-ERS guidelines and the recent update, $\mathrm{SSc}-\mathrm{PAH}$ patients (group 1 of the diagnostic classification), especially if young, should be treated with one or all 3 drugs approved for the treatment of endothelial dysfunction, to achieve a low-risk profile. If the patient remains or progresses to a high-risk profile despite maximal medical therapy, lung transplantation should be considered, paying particular attention during the screening to the comorbidities that may cause the procedure to fail. Older SSc-PAH patients, with risk factors for heart failure with preserved ejection fraction or with severe comorbidities (e.g. aortic stenosis, ischemic heart disease, etc.), should be carefully evaluated; for these patients, a therapeutic strategy based on an initial monotherapy with a possible switch to a combination therapy during the follow-up period, seems to be appropriate. Finally, a veno-occlusive pulmonary disease should be suspected if a patient with SSc-PAH, regardless of age, has an unexplained desaturation, a poor response to the specific therapy (or with pulmonary edema after the specific therapy) or radiological features suggestive of this complication.

The realization of this article has been possible thanks to an unconditional contribution by Janssen-Cilag

\section{REFERENCES}

1. Humbert M, Guignabert C, Bonnet S, et al. Pathology and pathobiology of pulmonary hypertension: state of the art and research perspectives. Eur Respir J. 2019; 53: 1801887.

2. Varga, J, Trojanowska M, Kuwana M. Pathogenesis of systemic sclerosis: recent insights of molecular and cellular mechanisms and therapeutic opportunities. J Sclerod Related Dis. 2017; 2: 137-52.

3. Simonneau G, Montani D, Celermajer DS, et al. Haemodynamic definitions and updated clinical classification of pulmonary hypertension. Eur Respir J. 2019; 53: 1801913.

4. Galiè N, Humbert M, Vachiery J-L, et al. 2015 ESC/ERS Guidelines for the diagnosis and treatment of pulmonary hypertension: The Joint Task Force for the Diagnosis and Treatment of 
Pulmonary Hypertension of the European Society of Cardiology (ESC) and the European Respiratory Society (ERS): Endorsed by: Association for European Paediatric and Congenital Cardiology (AEPC), International Society for Heart and Lung Transplantation (ISHLT). Eur Respir J. 2015; 46: 90375.

5. Kovacs G, Berghold A, Scheidl S, et al. Pulmonary arterial pressure during rest and exercise in healthy subjects: a systematic review. Eur Respir J. 2009; 34: 888-94.

6. Kawaguchi Y, Takagi K, Tochimoto A, et al. SAT048 Early detection and treatment for borderline pulmonary arterial hypertension in patients with systemic sclerosis in Japan. Ann Rheum Dis. 2015; 74: 834.

7. Kovacs G, Maier R, Aberer E, et al. Pulmonary arterial hypertension therapy may be safe and effective in patients with systemic sclerosis and borderline pulmonary artery pressure. Arthritis Rheum. 2012; 64: 1257-62.

8. Humbert M, Sitbon O, Chaouat A, et al. Pulmonary arterial hypertension in France: results from a national registry. Am J Respir Crit Care Med. 2006; 173: 1023-30.

9. D’Alonzo GE, Barst RJ, Ayres SM, et al. Survival in patients with primary pulmonary hypertension. Results from a national prospective registry. Ann Intern Med. 1991; 115: 343-9.

10. Benza RL, Gomberg-Maitland M, Miller DP, et al. The REVEAL registry risk score calculator in patients newly diagnosed with pulmonary arterial hypertension. Chest. 2012; 141 : 354-362.

11. Weatherald J, Boucly A, Launay D, et al. Haemodynamics and serial risk assessment in systemic sclerosis associated pulmonary arterial hypertension. Eur Respir J. 2018; 52: 1800678.

12. Boucly A, Cottin V, Nunes H, et al. Management and long-term outcomes of sarcoidosisassociated pulmonary hypertension. Eur Respir J. 2017; 50: 1700465.

13. Hoeper MM, Kramer T, Pan Z, et al. Mortality in pulmonary arterial hypertension: prediction by the 2015 European pulmonary hypertension guidelines risk stratification model. Eur Respir J. 2017; 50: 1700740.

14. Strange G, Gabbay E, Kermeen F, et al. Time from symptoms to definitive diagnosis of idiopathic pulmonary arterial hypertension: the delay study. Pulm Circ. 2013; 3: 89-94.

15. Rich S, Dantzker DR, Ayres SM, et al. Primary pulmonary hypertension. A national prospective study. Ann Intern Med. 1987; 107: 216-23.

16. Benza RL, Miller DP, Barst RJ, et al. An evaluation of long-term survival from time of diagnosis in pulmonary arterial hypertension from the REVEAL registry. Chest. 2012; 142 : 448-56.
17. Humbert M, Sitbon O, Chaouat A, et al. Survival in patients with idiopathic, familial, and anorexigen-associated pulmonary arterial hypertension in the modern management era. Circulation. 2010; 122: 156-163.

18. Humbert M, Sitbon O, Yaïci A, et al. Survival in incident and prevalent cohorts of patients with pulmonary arterial hypertension. Eur Respir J. 2010; 36: 549-55.

19. Benza RL, Miller DP, Gomberg-Maitland M, et al. Predicting survival in pulmonary arterial hypertension: insights from the Registry to Evaluate Early and Long-Term Pulmonary Arterial Hypertension Disease Management (REVEAL). Circulation. 2010; 122: 164-72.

20. Weatherald J, Boucly A, Launay D, et al. Haemodynamics and serial risk assessment in systemic sclerosis associated pulmonary arterial hypertension. Eur Respir J. 2018; 52: 1800678.

21. Mukerjee D, St George D, Coleiro B, et al. Prevalence and outcome in systemic sclerosis associated pulmonary arterial hypertension: application of a registry approach. Ann Rheum Dis. 2003; 62: 1088-93.

22. Chung L, Farber HW, Benza R, et al. Unique predictors of mortality in patients with pulmonary arterial hypertension associated with systemic sclerosis in the REVEAL registry. Chest. 2014; 146: 1494-1504.

23. Kolstad KD, Li S, Steen V, et al. Long-term outcomes in systemic sclerosis-associated pulmonary arterial hypertension from the Pulmonary Hypertension Assessment and Recognition of Outcomes in Scleroderma registry (PHAROS). Chest. 2018; 154: 862-71.

24. Condliffe R, Kiely DG, Peacock AJ, et al. Connective tissue disease-associated pulmonary arterial hypertension in the modern treatment era. Am J Respir Crit Care Med. 2009; 179: 151-7.

25. Campo A, Mathai SC, Le Pavec J, et al. Hemodynamic predictors of survival in sclerodermarelated pulmonary arterial hypertension. Am J Respir Crit Care Med. 2010; 182: 252-60.

26. Rubenfire M, Huffman MD, Krishnan S, et al. Survival in systemic sclerosis with pulmonary arterial hypertension has not improved in the modern era. Chest. 2013; 144: 1282-90.

27. Kawut SM, Taichman DB, Archer-Chicko CL, et al. Hemodynamics and survival in patients with pulmonary arterial hypertension related to systemic sclerosis. Chest. 2003; 123: 344-50.

28. Wigger GW, Zafar MA, Elwing JM. Improving adherence to pulmonary hypertension screening in patients with systemic sclerosis: Overcoming the provider-level barriers. J Scleroderma Relat Disord. 2020; 1-5 [Epub ahead of print].

29. Wald NJ. The definition of screening. J Med Screen. 2001; 8: 1 . 
30. World Health Organization. Cancer. Screening. Date last updated: February 3, 2017. Available from: www.who.int/cancer/prevention/diagnosis-screening/screening/en/ Accessed: February 5, 2019.

31. Bulliard J-L, Chiolero A. Screening and overdiagnosis: public health implications. Public Health Rev. 2015; 36: 8.

32. Vandecasteele E, Melsens K, Thevissen K, et al. Prevalence and incidence of pulmonary arterial hypertension: 10-year follow-up of an unselected systemic sclerosis cohort. J Scleroderma Relat Disord. 2017; 2: 196-202.

33. Hoeper MM, Lee SH, Voswinckel R, et al. Complications of right heart catheterization procedures in patients with pulmonary hypertension in experienced centers. J Am Coll Cardiol. 2006; 48: 2546-52.

34. Hachulla E, Gressin V, Guillevin L, et al. Early detection of pulmonary arterial hypertension in systemic sclerosis: a French nationwide prospective multicenter study. Arthritis Rheum. 2005; 52: 3792-800.

35. Vonk MC, Broers B, Heijdra YF, et al. Systemic sclerosis and its pulmonary complications in The Netherlands: an epidemiological study. Ann Rheum Dis. 2009; 68: 961-5.

36. Morrisroe K, Stevens W, Sahhar J, et al. Epidemiology and disease characteristics of systemic sclerosis-related pulmonary arterial hypertension: results from a real-life screening programme. Arthritis Res Ther. 2017; 19: 42.

37. Phung S, Strange G, Chung LP, et al. Prevalence of pulmonary arterial hypertension in an Australian scleroderma population: screening allows for earlier diagnosis. Intern Med J. 2009; 39: 682-91.

38. Coghlan JG, Denton CP, Grünig E, et al. Evidence-based detection of pulmonary arterial hypertension in systemic sclerosis: the DETECT study. Ann Rheum Dis. 2014; 73: 1340-9.

39. Vandecasteele E, Drieghe B, Melsens K, et al. Screening for pulmonary arterial hypertension in an unselected prospective systemic sclerosis cohort. Eur Respir J. 2017; 49: 1600227.

40. Nihtyanova SI, Schreiber BE, Ong VH, et al. Prediction of pulmonary complications and long-term survival in systemic sclerosis. Arthritis Rheumatol. 2014; 66: 1625-35.

41. Steen VD, Medsger TA. Changes in causes of death in systemic sclerosis, 1972-2002. Ann Rheum Dis. 2007; 66: 940-4.

42. Mercurio V, Diab N, Peloquin G, et al. Risk assessment in scleroderma patients with newly diagnosed pulmonary arterial hypertension: application of the ESC/ERS risk prediction model. Eur Respir J 2018; 52: 1800497.

43. Frost A, Badesch D, Gibbs JSR, et al. Diagnosis of pulmonary hypertension. Eur Respir J. 2019; 53: 1801904.

44. Gladue H, Altorok N, Townsend W, et al.
Screening and diagnostic modalities for connective tissue disease-associated pulmonary arterial hypertension: a systematic review. Semin Arthritis Rheum. 2014; 43: 536-41.

45. Young A, Nagaraja V, Basilious M, et al. Update of screening and diagnostic modalities for connective tissue disease-associated pulmonary arterial hypertension. Semin Arthritis Rheum. 2019; 48: 1059-67.

46. Weatherald J, Montani D, Jevnikar M, et al. Screening for pulmonary arterial hypertension in systemic sclerosis. Eur Respir Rev. 2019; 28: 190023.

47. Mukherjee M, Chung S-E, Ton VK, et al. Unique abnormalities in right ventricular longitudinal strain in systemic sclerosis patients. Circ Cardiovasc Imaging. 2016; 9: e003792.

48. Durmus E, Sunbul M, Tigen K, et al. Right ventricular and atrial functions in systemic sclerosis patients without pulmonary hypertension. Speckle-tracking echocardiographic study. Herz. 2015; 40: 709-15.

49. Hekimsoy V, Kaya EB, Akdogan A, et al. Echocardiographic assessment of regional right ventricular systolic function using twodimensional strain echocardiography and evaluation of the predictive ability of longitudinal 2D-strain imaging for pulmonary arterial hypertension in systemic sclerosis patients. Int J Cardiovasc Imaging. 2018; 34: 883-92.

50. Overbury RS, Murtaugh M A, Frech TM, et al. A normal diffusing capacity of the lungs for carbon monoxide is rare in incidental pulmonary arterial hypertension in systemic sclerosis: Data from the Pulmonary Hypertension Assessment and Recognition of Outcomes in Scleroderma cohort. J Scleroderma Relat Disord. 2018; 3: 237-41.

51. Steen VD, Graham G, Conte C, et al. Isolated diffusing capacity reduction in systemic sclerosis. Arthritis Rheum. 1992; 35: 765-70.

52. Steen V, Medsger TA. Predictors of isolated pulmonary hypertension in patients with systemic sclerosis and limited cutaneous involvement. Arthritis Rheum. 2003; 48: 516-22.

53. Mukerjee D, St George D, Knight C, et al. Echocardiography and pulmonary function as screening tests for pulmonary arterial hypertension in systemic sclerosis. Rheumatology (Oxford). 2004; 43: 461-6.

54. Degano B, Soumagne T, Delaye T, et al. Combined measurement of carbon monoxide and nitric oxide lung transfer does not improve the identification of pulmonary hypertension in systemic sclerosis. Eur Respir J. 2017; 50: 1701008.

55. Sivova N, Launay D, Wémeau-Stervinou L, et al. Relevance of partitioning DLCO to detect pulmonary hypertension in systemic sclerosis. PLoS One. 2013; 8: e78001. 
56. Overbeek MJ, Groepenhoff H, Voskuyl AE, et al. Membrane diffusion- and capillary blood volume measurements are not useful as screening tools for pulmonary arterial hypertension in systemic sclerosis: a case control study. Respir Res. 2008; 9: 68.

57. Saggar R, Khanna D, Furst DE, et al. Exercise-induced pulmonary hypertension associated with systemic sclerosis: four distinct entities. Arthritis Rheum. 2010; 62: 3741-50.

58. Steen V, Chou M, Shanmugam V, et al. Exercise-induced pulmonary arterial hypertension in patients with systemic sclerosis. Chest. 2008; 134: 146-51.

59. Kovacs G, Avian A, Wutte N, et al. Changes in pulmonary exercise haemodynamics in scleroderma: a 4-year prospective study. Eur Respir J. 2017; 50: 1601708.

60. Shaikh F, Anklesaria Z, Shagroni T, et al. A review of exercise pulmonary hypertension in systemic sclerosis. J Scleroderma Relat Disord. 2019; 4: 225-37.

61. Kovacs G, Olschewski H. Potential role of exercise echocardiography and right heart catheterization in the detection of early pulmonary vascular disease in patients with systemic sclerosis. J Scleroderma Relat Disord. 2019; 4: 219-24.

62. Codullo V, Caporali R, Cuomo G, et al. Stress Doppler echocardiography in systemic sclerosis: evidence for a role in the prediction of pulmonary hypertension. Arthritis Rheum. 2013; 65: 2403-11.

63. Hachulla AL, Launay D, Gaxotte V, et al. Cardiac magnetic resonance imaging in systemic sclerosis: a cross-sectional observational study of 52 patients. Ann Rheum Dis. 2009; 68: 1878-84.

64. Mavrogeni SI, Schwitter J, Gargani L, et al. Cardiovascular magnetic resonance in systemic sclerosis: "pearls and pitfalls". Semin Arthritis Rheum. 2017; 47: 79-85.

65. Mukerjee D, Yap LB, Holmes AM, et al. Significance of plasma N-terminal pro-brain natriuretic peptide in patients with systemic sclerosis-related pulmonary arterial hypertension. Respir Med. 2003; 97: 1230-6.

66. Williams MH, Handler CE, Akram R, et al. Role of N-terminal brain natriuretic peptide (NT-proBNP) in scleroderma-associated pulmonary arterial hypertension. Eur Heart J. 2006; 27: 1485-94.

67. Chighizola C, Meroni PL, Schreiber BE, et al. Role of N-terminal pro-brain natriuretic peptide in detecting clinically significant cardiac involvement in systemic sclerosis patients. Clin Exp Rheumatol. 2012; 30: S81-5.

68. Avouac J, Meune C, Chenevier-Gobeaux C, et al. Cardiac biomarkers in systemic sclerosis: contribution of high-sensitivity cardiac troponin in addition to $\mathrm{N}$-terminal pro-brain natriuretic peptide. Arthritis Care Res (Hoboken). 2015; 67: 1022-30.

69. Thakkar V, Stevens WM, Prior D, et al. Nterminal pro-brain natriuretic peptide in a novel screening algorithmfor pulmonary arterial hypertension in systemic sclerosis: a case-control study. Arthritis Res Ther. 2012; 14: R143.

70. Thakkar V, Stevens W, Prior D, et al. The inclusion of $\mathrm{N}$-terminal pro-brain natriuretic peptide in a sensitive screening strategy for systemic sclerosis-related pulmonary arterial hypertension: a cohort study. Arthritis Res Ther. 2013; 15: R193.

71. Allanore Y, Komocsi A, Vettori S, et al. N-terminal pro-brain natriuretic peptide is a strong predictor of mortality in systemic sclerosis. Int J Cardiol. 2016; 223: 385-9.

72. Shirai Y, Okazaki Y, Inoue Y, et al. Elevated levels of pentraxin 3 in systemic sclerosis: associations with vascular manifestations and defective vasculogenesis. Arthritis Rheumatol. 2015; 67: 498-507.

73. Zhao J, Mo H, Guo X, et al. Red blood cell distribution width as a related factor of pulmonary arterial hypertension in patients with systemic sclerosis. Clin Rheumatol. 2018; 37 : 979-85.

74. Simpson CE, Damico RL, Hummers L, et al. Serum uric acid as a marker of disease risk, severity, and survival in systemic sclerosis-related pulmonary arterial hypertension. Pulm Circ. 2019; 9: 2045894019859477.

75. Kampolis C, Plastiras SC, Vlachoyiannopoulos $\mathrm{PG}$, et al. The presence of anti-centromere antibodies may predict progression of estimated pulmonary arterial systolic pressure in systemic sclerosis. Scand J Rheumatol. 2008; 37: 278-83.

76. Steen VD, Lucas M, Fertig N, et al. Pulmonary arterial hypertension and severe pulmonary fibrosis in systemic sclerosis patients with a nucleolar antibody. J Rheumatol. 2007; 34: 2230-5.

77. Hoffmann-Vold AM, Fretheim H, Midtvedt O, et al. Frequencies of borderline pulmonary hypertension before and after the DETECT algorithm: results from a prospective systemic sclerosis cohort. Rheumatology. 2018; 57: 480-7.

78. Smith V, Scirè CA, Talarico R, et al. Systemic sclerosis: state of the art on clinical practice guidelines. RMD Open. 2018; 4: e000782.

79. Kumar U, Ramteke R, Yadav R, et al. Prevalence and predictors of pulmonary artery hypertension in systemic sclerosis. J Assoc Physicians India. 2008; 56: 413-7.

80. Shirai Y, Kuwana M. Complex pathophysiology of pulmonary hypertension associated with systemic sclerosis: potential unfavorable effects of vasodilators. J Scleroderma Relat Disord. 2017; 2: 69-134.

81. Mathai SC, Hummers LK, Champion HC, et 
al. Survival in pulmonary hypertension associated with the scleroderma spectrum of diseases: impact of interstitial lung disease. Arthritis Rheum. 2009; 60: 569-77.

82. Iudici M, Codullo V, Giuggioli D, et al. Pulmonary hypertension in systemic sclerosis: prevalence, incidence and predictive factors in a large multicentric Italian cohort. Clin Exp Rheumatol. 2013; 31: 31-6.

83. Hoeper MM, Lee SH, Voswinckel R, et al. Complications of right heart catheterization procedures in patients with pulmonary hypertension in experienced centers. J Am Coll Cardiol. 2006; 48: 2546-52.

84. Clements PJ, Tan M, McLaughlin VV, et al. The pulmonary arterial hypertension quality enhancement research initiative: comparison of patients with idiopathic PAH to patients with systemic sclerosis-associated PAH. Ann Rheum Dis. 2012; 71: 249-52.

85. Sobanski V, Launay D, Hachulla E, et al. Current approaches to the treatment of systemicsclerosis-associated pulmonary arterial hypertension (SSc-PAH). Curr Rheumatol Rep. 2016; $18: 10$.

86. Coghlan J, Denton CP. Aggressive combination therapy for treatment of systemic sclerosis-associated pulmonary hypertension. J Scleroderma Relat Disord. 2018; 3: 30-8.

87. Coghlan JG, Galiè N, Barbera JA, et al. Initial combination therapy with ambrisentan and tadalafil in connective tissue disease-associated pulmonary arterial hypertension (CTD-PAH): subgroup analysis from the AMBITION trial. Ann Rheum Dis. 2017; 76: 1219-27.

88. Gaine S, Chin K, Coghlan G, et al. Selexipag for the treatment of connective tissue diseaseassociated pulmonary arterial hypertension. Eur Respir J. 2017; 50: 1602493.

89. Khanna D, Gladue H, Channick R, et al. Recommendations for screening and detection of connective tissue disease-associated pulmonary arterial hypertension. Arthritis Rheum. 2013; 65: 3194-201.

90. Humbert M, Morrell NW, Archer SL, et al. Cellular and molecular pathobiology of pulmonary arterial hypertension. J Am Coll Cardiol. 2004; 43: S13-24.

91. Olsson KM, Palazzini M. Challenges in pulmonary hypertension: managing the unexpected. Eur Respir Rev. 2015; 24: 674-81.

92. Mineo G. Pulmonary veno-occlusive disease: the role of CT. Radiol Med. 2014; 119: 667-73.

93. Fuster V, Steele PM, Edwards WD, et al. Primary pulmonary hypertension: natural history and the importance of thrombosis. Circulation. 1984; 70: 580-7.

94. Moser KM, Fedullo PF, Finkbeiner WE, et al. Do patients with primary pulmonary hypertension develop extensive central thrombi? Circulation. 1995; 91: 741-5.
95. Hervé P, Humbert M, Sitbon O, et al. Pathobiology of pulmonary hypertension. The role of platelets and thrombosis. Clin Chest Med. 2001; 22: 451-8.

96. Frank H. The effect of anticoagulant therapy in primary and anorectic drug-induced pulmonary hypertension. Chest. 1997; 112: 714-21.

97. Olsson KM. Anticoagulation and survival in pulmonary arterial hypertension: results from the Comparative, Prospective Registry of Newly Initiated Therapies for Pulmonary Hypertension (COMPERA). Circulation. 2014; 129: 57-65.

98. Galiè N, Delcroix M, Ghofrani A, et al. Anticoagulant therapy does not influence longterm outcomes in patients with pulmonary arterial hypertension (PAH): insights from the randomised controlled SERAPHIN trial of macitentan. Eur Heart J. 2014; 35: 10.

99. Preston RJ, Roberts KE, Miller DP, et al. Effect of warfarin treatment on survival of patients with pulmonary arterial hypertension $(\mathrm{PAH})$ in the Registry to Evaluate Early and Long-Term PAH Disease Management (REVEAL). Am J Respir Crit Care Med. 2014; 189: A2464.

100. Palazzini M. Anticoagulant treatment in patients with pulmonary arterial hypertension associated with systemic sclerosis: More shadows than lights. J Scleroderma Relat Disord. 2018; 3: 39-42.

101. Galiè N, Manes A, Palazzini M. Exercise training in pulmonary hypertension: improving performance but waiting for outcome. Eur Heart J. 2016; 37: 45-8.

102. Galiè N, Channick RN, Frantz RP, et al. Risk stratification and medical therapy of pulmonary arterial hypertension. Eur Respir J. 2019; 53: 1801889.

103. Galiè N, McLaughlin VV, Rubin LJ, et al. An overview of the 6th World Symposium on Pulmonary Hypertension. Eur Respir J. 2019; 53: 1802148.

104. Sitbon O, Humbert M, Jagot JL, et al. Inhaled nitric oxide as a screening agents for safely identifying responders to oral calcium-channel blockers in primary pulmonary hypertension. Eur Respir J. 1998; 12: 265-70.

105. Sitbon O, Humbert M, Jaïs X, et al. Longterm response to calcium channel blockers in idiopathic pulmonary arterial hypertension. Circulation. 2005; 111: 3105-11.

106. Nootens M, Kaufmann E, Rich S. Short-term effectiveness of nifedipine in secondary pulmonary hypertension. Am J Cardiol. 1993; 71: 1475-6.

107. Nathan SD. Pulmonary hypertension in chronic lung disease and hypoxia. Eur Respir J. 2019; 53: 1801914.

108. Kylhammar D, Kjellström B, Hjalmarsson $\mathrm{C}$, et al. A comprehensive risk stratification 
at early follow-up determines prognosis in pulmonary arterial hypertension. Eur Heart J. 2018; 39: 4175-81.

109. Hoeper MM, Kramer T, Pan Z, et al. Mortality in pulmonary arterial hypertension: prediction by the 2015 European pulmonary hypertension guidelines risk stratification model. Eur Respir J. 2017; 50: 1700740.

110. Boucly A, Weatherald J, Savale L, et al. Risk assessment, prognosis and guideline implementation in pulmonary arterial hypertension. Eur Respir J. 2017; 50: 1700889.

111. Galiè N, Barbera JA, Frost AE, et al. Initial use of ambrisentan plus tadalafil in pulmonary arterial hypertension. $\mathrm{N}$ Engl J Med. 2015; 373: 834-44.

112. Lang IM, Palazzini M. The burden of comorbidities in pulmonary arterial hypertension. Eur Heart J Suppl. 2019; 21: K21-8.

113. Galiè N, Corris P, Frost A, et al. Updated treatment algorithm of pulmonary hypertension. J Am Coll Cardiol. 2013; 62: D60-72.

114. Hoeper MM, Simonneau G, Corris PA, et al. RESPITE: switching to riociguat in pulmonary arterial hypertension patients with inad- equate response to phosphodiesterase-5 inhibitors. Eur Respir J. 2017; 50: 1602425.

115. Pulido T, Adzerikho I, Channick RN, et al. Macitentan and morbidity and mortality in pulmonary arterial hypertension. $\mathrm{N}$ Engl $\mathbf{J}$ Med. 2013; 369: 809-18.

116. Ghofrani HA, Galiè N, Grimminger F, et al. Riociguat for the treatment of pulmonary arterial hypertension. N Engl J Med. 2013; 369: 330-40.

117. Sitbon O, Channick R, Kelly C, et al. Selexipag for the treatment of pulmonary arterial hypertension. N Engl J Med. 2015; 373: 2522-33.

118. Lemmers JM, Fretheim H, Knaapen HK, et al. Selexipag treatment in patients with systemic sclerosis-associated pulmonary arterial hypertension in clinical practice, a case series. J Scleroderma Relat Disord. 2020; 1-5 [Epub ahead of print].

119. Hachulla E. Survival improved in patients aged $\leq 70$ years with systemic sclerosis-associated pulmonary arterial hypertension during the period 2006 to 2017 in France. Chest. 2020; 157: 945-54. 